Portland State University

PDXScholar

\title{
Algorithms for Studying the Impact of Travel Time Reliability Along Multisegment Trucking Freight Corridors
}

Miguel Figliozzi

Portland State University, figliozzi@pdx.edu

Nikki Wheeler

Portland State University

Eric Albright

Portland State University

Lindsay Walker

Portland State University

Shreemoyee Sarkar

Portland State University Fortlow this and additional works at: https://pdxscholar.library.pdx.edu/cengin_fac

Part of the Civil Engineering Commons, Environmental Engineering Commons, and the Transportation Serejinextipagedor foddjitional authors

Let us know how access to this document benefits you.

\section{Citation Details}

Figliozzi, Miguel; Wheeler, Nikki; Albright, Eric; Walker, Lindsay; Sarkar, Shreemoyee; and Rice, Danielle, "Algorithms for Studying the Impact of Travel Time Reliability Along Multisegment Trucking Freight Corridors" (2011). Civil and Environmental Engineering Faculty Publications and Presentations. 248. https://pdxscholar.library.pdx.edu/cengin_fac/248

This Post-Print is brought to you for free and open access. It has been accepted for inclusion in Civil and Environmental Engineering Faculty Publications and Presentations by an authorized administrator of PDXScholar. Please contact us if we can make this document more accessible: pdxscholar@pdx.edu. 


\section{Authors}

Miguel Figliozzi, Nikki Wheeler, Eric Albright, Lindsay Walker, Shreemoyee Sarkar, and Danielle Rice 


\title{
Algorithms to Study the Impacts of Travel Time Reliability along Multi- Segment Trucking Freight Corridors
}

\author{
*Miguel A. Figliozzi \\ Nikki Wheeler \\ Eric Albright \\ Civil and Environmental Engineering \\ Portland State University \\ Lindsay Walker \\ Urban and Regional Planning \\ Portland State University \\ Shreemoyee Sarkar \\ Computer Science \\ Portland State University \\ Danielle Rice \\ Mathematics and Statistics \\ Portland State University \\ *Corresponding Author - figliozzi@pdx.edu \\ Associate Professor \\ Department of Civil \& Environmental Engineering \\ Portland State University \\ PO Box 751 \\ Portland, OR 97207
}

Paper Presented at the

$90^{\text {th }}$ Annual Meeting of the Transportation Research Board

January 23-27, 2011

FORTHCOMING 2011 Transportation Research Record 


\begin{abstract}
Performance measures allow planners and engineers to monitor and evaluate transportation facilities or projects and to justify the allocation of funds among alternative transportation improvement options. To capture the impact of corridor congestion on freight vehicles, new tools and methodologies are developed to analyze data from commercial vehicles and produce performance measures like travel time, speed and travel time reliability. Since long freight corridors are comprised of segments with potentially different reliability characteristics, the objective of this paper is to develop a programming logic that will use available truck GPS (Geographical Positioning System) data to: (a) identify natural segments or regions in a corridor between urban centers, interstate junctions, or rural areas and (b) estimate corridor wide impacts of travel time unreliability. The case study presented here investigates the Interstate 5 (I-5) corridor in Oregon. After identifying corridor segments, this research applies statistical techniques to compute vehicle travel time and reliability for freight movements within each segment. The proposed methodology has been used successfully to indentify distinct segments and characteristics of travel time reliability in freight corridors. Travel time information was used to compute cost impacts of delays within rural and urban areas along the I-5 corridor. This research presents an advance in the processing and aggregation of GPS truck data to produce succinct yet informative performance measures and segments.
\end{abstract}

Keywords: commercial vehicles, congestion, GPS, segments, performance 


\section{INTRODUCTION}

Since the adoption of performance measures (PM) by departments of transportation, the traditional focus has been on the movement of passenger vehicles (1). As a result, PM currently employed by many agencies may not appropriately capture the needs of all roadway users, including freight vehicles. Currently, there are neither specific freight performance measures (FPMs) in use by public agencies nor rough estimations of travel time reliability to/from major economic centers. For the freight industry, delay and congestion not only negatively impact the businesses that rely on efficient and timely deliveries, but also increase vehicle emissions and the cost of transporting goods. In order to improve the functionality of transportation networks and make efficient use of funds, it is crucial that public agencies develop tools to assess existing system performance for all modes.

Just-in-time production systems reduce the amount of inventory available at distribution centers or retailers and increase the need for products/parts to arrive at the scheduled time. For example, a late delivery may delay production and/or product delivery as scheduled, causing manufacturers to incur steep financial losses. As a result, carriers may also face steep penalties and additional costs when a breakdown in the supply chain takes place. Without a reliable transportation network, it is difficult for carriers to schedule a departure time that will ensure an on-time arrival at the destination.

Although this research is specific to one freight mode (trucking), the research and tools developed here can be expanded and adapted to develop PM for other modes. This paper uses reliability of travel time as the PM for freight movement, defined as the time taken by a driver to travel between an origin and destination. NCHRP 618 recommends the use of $90^{\text {th }}$ and $95^{\text {th }}$ percentile travel times for a given route or trip as the simplest indicator of travel time reliability. The $90^{\text {th }}$ and $95^{\text {th }}$ percentile travel times are intended to reflect the travel time delays that can occur during heavy congestion (2). Additionally, travel time information is easy to interpret, and is desired by the general traveling public, as well as freight carriers. After identifying segments for analysis on the I-5 corridor, this research uses $50^{\text {th }}, 80^{\text {th }}$ and $95^{\text {th }}$ percentile travel time to represent variability in rural and urban areas.

\section{BACKGROUND AND LITERATURE REVIEW}

Mobility affects the freight industry because it limits the ability of vehicles to move between origins and destinations (3). Measures used to quantify mobility include travel time, reliability, and delay. These PM are highly dependent on the location of a corridor segment (e.g., rural vs. urban). Urban centers tend to have greater traffic volumes throughout the day, especially in morning and evening peak periods, which contribute to recurring congestion. Rural traffic volumes and mobility tend to be more consistent throughout the day. Therefore, it is important to develop tools that can properly identify roadway segments with similar land use characteristics.

Loop sensor data has been successfully used to identify truck volume and acquire travel time and speed information on interstates. In addition, truck transponder data (weigh-in-motion data) have also been used to gather travel time information as well as characteristics of the freight vehicle and load. Recently, Geographical Positioning System (GPS) technologies have emerged as a method for collecting freight specific data. McCormack et al. (4) and Quiroga et al. (5) have described the challenges associated with the utilization of GPS data to develop PM for freight and passenger vehicles. 


\section{Loop Sensor Data}

Loop sensor data has been used to estimate freeway performance (e.g., travel time, speed, and vehicle count) for general-purpose vehicles and to identify and study bottlenecks at a regional and link level $(6,7)$. However, loop sensors are limited in their ability to differentiate between vehicle types traveling along a freeway and to provide disaggregate data by mode. Researchers at the University of Washington have studied the reliability of dual loop detectors in providing accurate vehicle count and speed results by vehicle type $(8,9)$. These researchers have also use single loop detectors to differentiate between vehicles by incorporating video footage. Although this method may be time consuming and requires calibrations, their findings show that there is promise in integrating single loop detectors with video footage to differentiate between general purpose vehicles and freight vehicles with reasonable accuracy in count and speed estimates. However, dual loop detectors were found to be less reliable and could not reasonably estimate between vehicle types during congested periods (8).

\section{Truck Transponder Data}

Since the early 2000's, researchers have investigated the use of truck transponder data as a source for truck travel time information. If a transponder-equipped vehicle can be tracked at two sequential Weigh-in-Motion (WIM) stations, their timestamps can be used to generate information regarding the trip travel time and later aggregated to produce freeway link performance measures such as travel time distributions and reliability. This approach is similar to methods used along toll roads, and more recently, methods that incorporate Media Access Control (MAC) addresses from portable devices to study arterial performance measures.

However, truck transponder data presents several challenges (10). First, there are generally long distances between WIM stations. A freight vehicle has the opportunity to stop, rest, refuel or make deliveries before it is tracked at the next station. Algorithms must be incorporated to filter out trucks that stop while traveling through the corridor because their slower travel time information would severely bias the results Secondly, the number of trucks equipped with transponders is relatively low and a large sample size must be required to accurately estimate link travel time based on the truck data.

\section{Truck GPS Data}

Commercial GPS technologies are now emerging as an effective form of data collection and are showing potential in contributing to the study of freight movements. However, there are challenges in utilizing GPS data provided by the freight industry.

The first challenge is related to the availability of GPS data. Although many carriers are now using GPS to monitor fleets, a carrier's scheduling and logistics practices are proprietary and not commonly shared. Early work by Greaves and Figliozzi (11) in Australia discussed the use of passive GPS devices to identify truck trips and presented future applications and limitations of the data source. Recent research efforts by McCormack et al. (4) have presented the challenges involved in acquiring data; this work highlighted the process of purchasing GPS data from private vendors to establish a GPS freight database with success.

The second challenge is truck drivers' behavior. Trucks behave much differently than passenger vehicles since truck drivers have mandatory rest periods, must follow lane restrictions, must adhere to strict schedules, and must make stops for deliveries and pickups throughout the day. This type of travel behavior can be captured by GPS data more readily than other types of data. However, as previously discussed in the utilization of truck transponder data, algorithms must be developed to identify and recognize these different behaviors to study local and freeway 
performance, as well as travel between key origin-destination pairs.

The Federal Highway Administration (FHWA) is currently sponsoring research at several universities nationwide, and in a partnership with the American Transportation Research Institute (ATRI), GPS data from freight vehicles have been made accessible for universities to investigate new methods for developing FPM in urban and rural areas. This research utilizes such data generously provided by ATRI.

\section{METHODOLOGY FOR CORRIDOR SEGMENTATION}

A review of existing literature investigating freight performance measures using freight specific data (e.g., WIM, commercial GPS) informed the methodologies developed in this research to study travel time reliability on multi-segment corridors.

Commercial GPS data from ATRI, covering the I-5 corridor in Oregon, was used in this research. Our approach utilized relies on increases and decreases in truck volume along the corridor to identify changes in segments (i.e., urban segments, rural segments). Truck volume is utilized because volume or traffic flow per lane is the key factor associated with congestion and reduced travel speed as indicated in the Highway Capacity Manual (HCM). Additionally, along a freeway corridor, changes in traffic volumes take place at interchanges. We assume that segments along corridors (as well as the total number of lanes) are defined between interchanges. If a finer spatial resolution is needed after an initial segmentation using volumes, a second segmentation using speeds can be applied. The same methodology would apply using speeds instead of volumes.

As discussed in the literature review, a challenge of working with commercial GPS data is that data from trucks experiencing congestion (exhibiting lower speeds), may be confused with trucks experiencing longer travel times for reasons unrelated to congestion. If proper filtering methods are not used, trucks that have left the interstate to refuel, make deliveries, or rest may be analyzed and create bias in the data set. Additionally, it is understood that different segments along a corridor will have different speed distributions, which also vary by time of day. For this reason, truck volume is used initially to identify segments of analysis, then, travel speeds are utilized to remove these outliers (e.g., observations which have been identified to have slower speeds for reasons unrelated to congestion). In this way, trucks traveling through different segments can be filtered based on travel time characteristics of each segment.

The following section describes the methods utilized for data handling and the algorithmic description of the process used to determine potential segments based on geographic location (rural or urban) along the Oregon I-5 corridor.

\section{Data description}

The analysis is performed using GPS data from commercial trucks along I-5; the data was provided by ATRI. Each record or observation provides a unique truck ID, timestamp, latitude and longitude of the trucks. Using ArcGIS linear referencing tool, every GPS latitude-longitude reading is mapped to a milepost measure. Using the milepost measures, the direction of travel is also determined for every truck and designated as, northbound (NB) or southbound (SB). The GPS data is then arranged in database tables using the postgreSQL database tools and finally simulated to generate travel time distributions using scripts written in PHP and Shell.

\section{Segment Distribution}

In order to identify segments along the corridor the following sequence is followed: 
1. Truck counts are determined for every mile and travel direction (NB or SB) by applying queries and scripts on the previously arranged database tables.

2. A cumulative truck count function (CTCF) is drawn for the cumulated truck counts. This CTCF allows the identification of any sudden rise and fall in truck counts occurring in a particular area of the corridor.

3. Smoothing is performed on the CTCF using a moving average of length 20 miles.

4. The above three processes are repeated for different months that fall on different seasons around the year to capture any truck counts seasonal effects.

Segment Analysis

The truck density patterns are analyzed by considering two factors:

1. Location of significant changes in truck density, and

2. Time of the year and seasonal variations.

Using the truck density patterns, the corridor is broken into a number of segments falling within rural and urban areas.

\section{SEGMENTATION RESULTS}

The results presented and described herein correspond to I-5 in the northbound (NB) direction only. Commercial GPS data for four months (April, July, October and December) in 2007 were analyzed. These months were chosen to represent seasonal variations in truck travel and traffic volumes. Truck counts were first determined for one-mile segments. The counts are similar for April, July, and December. Counts in the October are consistently the lowest. This paper presents results for the month of July as the counts are highest or second highest along the corridor. Figure 1 presents the truck counts per segment for the four months analyzed.

Figure 2 presents the cumulative truck count function (CTCF) for NB I-5 during the month of July 2007 given as a percentage of the total count per mile (left). It was verified that the same sudden rise and fall in truck counts throughout the corridor take place at the same locations across the four chosen months (i.e., the cumulative distribution plots for the chosen months are similar to the plot shown for July). To present a clearer trend regarding the rise and fall in truck count rates, the data was smoothed by averaging over a 20 -mile length (i.e., a moving average of 20 miles in length) (right).

The start and end of each segment, and nearby points of interest (urban areas, major highway junctions, etc.) are identified in Table 1 . Table 1 presents each segment ID, the segment mileposts, truck counts, and nearby locations or points or interest. Truck count results reflect the month of July 2007 only.

As expected, higher truck counts tend to occur in segments near urban areas (e.g., Eugene-Corvallis-Salem). In the Portland area, counts are lower due to an alternative truck route (Interstate 205) and the truck traffic splits. Figure 3 presents the identified segment locations for NB I-5. As depicted in the maps and supported in the results presented in Table 1, segments in northern Oregon (segments 6-7) correspond to urban areas with higher truck count density (counts/mile), while segments in southern Oregon (segments 1-5) correspond to rural areas with lower truck count density.

Segmentation also should include other considerations such as land use and posted speed limits. For example, in Oregon, speed limits in urban areas are lower than in rural areas. Additionally, to remove outliers, time of day level can affect the posted speed limit (night vs. 
day). Similarly, recurrent congestion levels affect the lower speed thresholds. The impact of speed thresholds on travel time distributions is described in the subsequent sections.

Finally, identified segments can be mapped against GIS data (e.g., against Highway Performance Monitoring System or HPMS data) in order to validate the results of the proposed corridor segmentation. With corridor segments identified, each corresponding to rural or urban areas, it is possible to analyze segments independently.

\section{METHODOLOGY FOR THE ESTIMATION OF RELIABLE TRAVEL TIMES}

This section presents the algorithm used to estimate truck travel time distributions for each segment. The parameters, variables, assumptions, and output of the algorithm employed to estimate the travel time distribution is presented below.

\section{Parameters:}

$\mathrm{m}_{0 i}$ : Initial milepost for segment $i$, (i.e., the start point of a segment in miles).

$\mathrm{m}_{1 i}$ : Final milepost for segment $i$, (i.e., the end point of a segment in miles).

$\mathrm{m}_{1 i}-\mathrm{m}_{0 i}$ : Length of segment in miles.

$\mathrm{b}_{r i}: \mathrm{f}_{i}\left(\left|\mathrm{~m}_{1 i}-\mathrm{m}_{0 i}\right|\right)$ - Buffer radius or the radius of influence in miles around the start and end points of a segment where $\left|\mathrm{m}_{1 \mathrm{i}}-\mathrm{m}_{0 \mathrm{i}}\right|$ is the length of the segment that we choose.

$\mathrm{f}_{i}$ : factor to determine the size of the radius of influence

mean $_{\text {cur }}$ : Total time/number of trucks - mean of the timestamp readings for current segment being analyzed.

mean $_{\text {prev }}$ : Mean of timestamp readings for a previous segment.

$\mathrm{n}_{\text {min, } i:}$ minimum number of trucks trips that is acceptable.

$\mathrm{s}_{\min , i}:$ minimum acceptable truck speed.

$\mathrm{s}_{\max , i}:$ maximum acceptable truck speed.

\section{Variables:}

$\mathrm{m}_{\text {start }}$ : Actual start point for a truck in miles.

$\mathrm{m}_{\text {end }}$ : Actual end point for a truck in miles.

$\mathrm{n}_{\text {actual : }}$ Actual number of truck trips in a segment as obtained from the data.

\section{Assumptions:}

The vehicle travel time within a segment is normally distributed.

\section{Outputs:}

$\mathrm{t}_{95}$ : Travel time $95 \%$ percentile.

$\mathrm{t}_{80}$ : Travel time $80 \%$ percentile.

$\mathrm{t}_{50}$ : Travel time $50 \%$ percentile.

\section{Algorithmic description:}

\section{0 . Preprocessing}

Determine the minimum number of trucks or observations $\left(\mathrm{n}_{\text {min, }, i}\right)$ required for each segment $i$. The value of $\mathrm{n}_{\min , i}$ will depend on the required accuracy for the travel time estimations. Clearly, the number of valid observation will depend on the following factors: (a) segment length, (b) time period, and (c) density of counts the given segment 
and time period.

1. Initiate the iterations

Pick the first segment, $i=1$

2. Identify trips start and end points

A truck may have several readings in a given segment. In order to find the most representative travel time for the segment, for each truck in the segment do:

(a) Find $m_{\text {start }}$ that is closest to $m_{0 i}$ and lies within the buffer radius $b_{\text {ri. }}$

(b) Find the end point of the truck trip $m_{\text {end }}$ for the same day that is closest to $m_{1 i}$ and lies within the buffer radius $b_{\text {ri }}$.

(c) If steps (a) and (b) are successful then a travel time is obtained and added to the list of travel times for the segment.

3. Number of travel time observations

Count the number of truck trips obtained for the segment or the list size: $\mathrm{n}_{\text {actual }}$

4. Verify that $\mathrm{n}_{\text {actual }} \geq \mathrm{n}_{\min , \mathrm{i}}$

If the number of minimum observations is not reached, output a warning message. It would be necessary to add more observations: (a) increasing the time period length or (b) finding a segment that better represent truck trips or GPS observation intervals. Go back to step 1 and continue with the next segment $i=i+1$

5. Calculate travel times

Calculate travel time distribution for all the trucks by finding the difference in the timestamp between their consecutive $\mathrm{m}_{\text {start }}$ and $\mathrm{m}_{\text {end }}$ readings. This time difference is the actual time required by a truck to cross the segment.

\section{Remove outliers}

Calculate the minimum and maximum travel time ranges based on the length of the segment and the value of the parameters $\mathbf{s}_{\min , i}$ and $\mathrm{s}_{\max , i}$. Parameters $\mathrm{s}_{\min , i}$ and $\mathrm{s}_{\max , i}$ should be segment dependent because typical travel speeds are affected by land use (e.g., rural vs. urban), posted speed limits, and congestion.

- Remove from the list of travel times that are outside the range of acceptable travel times. For example, trucks whose travel time exceeds the upper threshold may have stopped to rest, refuel, or make deliveries.

- Recalculate the size of the list of observations $\mathrm{n}_{\text {actual }}$

7. Verify that $\mathrm{n}_{\text {actual }} \geq \mathrm{n}_{\min , i}$

If the number of minimum observations is not reached, output a warning message. It is necessary to examine what is causing a high number of outliers. In some cases it would be possible to reincorporate trucks/observations if it is detected that an actual stop was made and this bias is properly removed from the data.

If after examining the outliers still holds that $n_{\text {actual }} \geq n_{\min }$, then, segment length or speed threshold parameters may have to be reexamined. Go back to step 1 and continue with the 
next segment $i=i+1$.

8. Estimate descriptive statistics for segment $i$

Estimate desired percentiles, mean, standard deviation, skewness, etc.

9. Repeat the analysis for next segments, $i=i+1$ until completing all segments.

For the NB I-5 July 2007 data, the algorithm described in this section was applied to each of the milepost segments indentified earlier. Results are presented in Table 2 . The free-flow travel time is computed by dividing the segment length with the trucks free-flow speed assumed to be 60 miles/hr. The buffer $\left(b_{r i}\right)$ is assumed to be $10 \%$ of the segment length and the threshold travel speeds are assumed to be $s_{\min , i}=10 \mathrm{mph}$ and $\mathrm{s}_{\max , i}=80 \mathrm{mph}$.

The actual number of truck trips identified were sufficient to perform the travel time calculations on each segment, (i.e., with the assumed parameters $n_{\text {actual }} \geq n_{\text {min,i }}$ was always satisfied). This may not be the case if the period of analysis is smaller. The results for a shorter period of time, typical afternoon rush hour 16:30-18:30, are presented in Table 3.

\section{ANALYSIS OF THE RESULTS}

The comparison of the results contained in Table 2 and 3 indicate that in almost all cases the travel time percentiles are higher for the 24 hour period. This is an indication that the low speed threshold $\mathrm{s}_{\min , i}=10 \mathrm{mph}$ is not adequate since travel times during peak times should be longer than travel times that include low traffic periods (e.g., night time).

The impact of a low speed threshold can be easily appreciated when observing a graph of the travel time distribution. Figure 4 presents the Gaussian kernel probability distribution graphs for the computed truck travel times over a period of 24 hours (Table 2 values). Figure 5 presents the Gaussian kernel probability distribution graphs for the computed truck travel times over a period between 15:30-18:30 (Table 3 values). The 95\% percentile travel time is noted on each figure. To facilitate comparisons and the calculation of travel speeds, segment 1 of length $\mathrm{m}_{1,1}-$ $\mathrm{m}_{0,1}=30$ miles and segment 8 of length $\mathrm{m}_{1,8}-\mathrm{m}_{0,8}=20$ miles are chosen.

From the study of the graphs presented in Figure 4 and Figure 5, it is clear that there is a long tail of observations after a 1.25 hour travel time for segment 1 and a 0.8 hour travel time for segment 8 . The corresponding speeds are 24 and $25 \mathrm{mph}$ respectively. Hence, the $\mathrm{s}_{\min , i}=10$ $\mathrm{mph}$ threshold is not adequate and is capturing travel times that include intermediate stops rest, refuel, or deliveries. In some cases, when there are four or more observations for the same truck within the segment, an additional analysis of outliers indicates that trucks were indeed stopped. When there are only two observations for the same truck in the segment, it is impossible to determine the cause of the excessive travel time from the truck data alone.

It is possible to see the impact of $s_{\min , I}$ looking at the distributions of the coefficients of variations for all segments as depicted in Figure 6. A change in the slope is observed around 25 $\mathrm{mph}$ and the distributions tend to have less variability when $\mathrm{s}_{\min , I}>35 \mathrm{mph}$. However, increasing $\mathbf{S}_{\min , i}$ also increases the risk of wrongfully removing observations that reflect congested conditions if bottleneck travel times are less than $\mathrm{s}_{\min , i}$ and the length of the bottleneck is considerable in relation to the segment length (12). The value of the parameter $s_{\max , i}$ is less significant since the left tail is naturally bounded by zero.

The most efficient method to calibrate $s_{\text {min, } i}$ is to use an alternative travel time estimation system such as loop-detectors. This method was successfully applied in the Portland region (13). Future research should include application of these methods to estimate travel time distributions 
such as log-normal or beta. These should be investigated because these distributions may prove to be a better fit. Additionally, smaller case studies could be conducted on segments over different times of day (or weekend versus weekday) in order to capture variation in travel time distributions, and compare among segments of differing type (urban versus rural). The analysis presented in this research serves as a launching point for further studies and investigations, and offers an example of how the methods in this research may be applied.

\section{ESTIMATED COST OF TRAVEL TIME RELIABILITY}

The impact of travel time reliability on operating and travel time costs can be estimated using the predicted travel times with 50\%, 80\% and 95\% percentile across each segment of the corridor. The average operating cost figure was derived during recent research by ATRI, and used to estimate operating cost per mile - this figure was $\$ 83.68$ per hour (14). The average value of time figure for freight vehicles in Oregon was adjusted to reflect 2010 prices, and used to estimate travel time cost per mile-this figure was $\$ 27.85$ per hour (15).

For each segment along the corridor, Figure 7 presents the daily operating cost per mile per freight vehicle, and daily travel time cost per mile per freight vehicle for travel below freeflow conditions; (i.e., the cost of delay for travel time at $50 \%, 80 \%$ and $90 \%$ confidence intervals). As shown, there are greater costs per mile per freight vehicle near urban areas, with the Portland-Vancouver and surrounding cities achieving the highest cost per mile per freight vehicle (segments 9 and 10). Additionally, the urban areas show greater differences in costs among the travel times at 50\%, $80 \%$ and $90 \%$ percentiles. Smaller cities, such as Eugene and Salem (segments 6 and 8), also achieve moderate cost per mile per freight vehicle, as does the area surrounding the key junction of I-5 and Pacific Highway (segment 4). The remaining rural areas achieve lower cost per mile, with little difference between travel times with $50 \%, 80 \%$ and $90 \%$ confidence.

Higher costs reflected near urban centers are a direct result of the increase in the variability (i.e., decrease in reliability) of travel time within these areas, caused by recurring and nonrecurring congestion. Variability in travel time presents a challenge particularly for the freight industry, as carriers must meet scheduling demands of their customers. Figure 8 illustrates a comparison between free-flow travel time and travel time at 50\%, 80\%, 90\% percentiles by depicting the increase in cost above free-flow cost.

\section{CONCLUSIONS}

The estimation of travel time reliably plays a crucial role in timely delivery of goods. As discussed in this report, the estimation of travel time is dependent on several factors such as the time of operation, the location of the corridor and its characteristics (e.g.., urban or rural segments, time of day). This paper discusses a methodology that can estimate the travel time distributions across a particular segment of a corridor. More accurate travel time distributions are useful since they can help meet a carrier's departure and arrival time constraints.

Long freight corridors are comprised of segments with potentially different reliability characteristics. This research developed algorithms that use available truck GPS data to: (a) identify corridor natural segments or regions (urban centers, interstate junctions, rural areas) and (b) estimate corridor wide impacts of travel time unreliability. The method was applied successfully to segments of the Oregon I-5 corridor. The impact of travel time reliability on operating and travel time costs were estimated using the predicted travel times with 50\%, $80 \%$ and $95 \%$ percentiles. Higher costs reflected near urban centers are a direct result of the increase in the variability (decrease in reliability) of travel time within these areas, caused by recurring 
and nonrecurring congestion.

Among the parameters that are needed to filter outliers, the low speed threshold is the most critical. Lower low speed thresholds lead to unrealistic travel time distributions, higher low speed thresholds increases the risk of filtering out observations that represent real-world congested travel times. 


\section{ACKNOWLEDGEMENTS}

The authors would like to thank Jeffrey Short from the American Transportation Research Institute and Crystal Jones from Federal Highway Administration for their help in acquiring and dealing with GPS data. The authors gratefully acknowledge the Oregon Transportation, Research and Education Consortium (OTREC) and Federal Highway Administration for sponsoring this research. Any errors or omissions are the sole responsibility of the authors. 


\section{REFERENCES}

1. Harrison, Robert, and Mike Schofield. Developing Appropriate Freight Performance Measures for Emerging Users. Publication SWUTC/07/473700-00073-1. Southwest Region university Transportation Center Texas Transportation Institute, 2007.

2. Cambridge Systematics, Inc., Dowling Associates, Inc., System Metrics Group, Inc., and Texas Transportation Institute. Cost-Effective Performance Measures for Travel Time Delay, Variation, and Reliability. NCHRP 618. Transportation Research Board of National Academies, 2009.

3. Cambridge Systematics, Inc., PB Consult, Inc., and Texas Transportation Institute. Performance Measures and Targets for Transportation Asset Management. NCHRP 551. Transportation Research Board of National Academies, 2006.

4. McCormack, E., X. Ma, C. Klowcow, A. Currarei, and D. Wright. Developing a GPS-Based Truck Freight Performance Measure Platform. Transportation Northwest Regional Center X, Washington State Transportation Center and Washington State Department of Transportation, April 2010.

5. Quiroga, C., and D. Bullock. Travel Time Studies With Global Positioning and Geographic Information Systems: An Integrated Methodology. Transportation Research Part C, Vol. 6, 1998, pp. 101-127.

6. Bertini, R., S. Hansen, A. Byrd, and T. Yin. Experience Implementing the ITS Archived Data User Service in Portland, Oregon. Transportation Research Record: Journal of the Transportation Research Board, No. 1917, Transportation Research Board of the National Academies, Washington, D.C., 2005, pp. 90-99.

7. Wieczorek, J., L. Huan, R. Fernandez-Moctezuma, and R. Bertini. Integrating an Automated Bottleneck Detection Tool into an Online Freeway Data Archive. In 88th Annual Meeting of Transportation Research Board. CD-ROM. Transportation Research Board of the National Academies, Washington, D.C., 2009.

8. Nihan, N. L., X. Zhang, Y. Wang, and P. Briglia. Evaluation of Dual-Loop Data Accuracy Using Video Ground Truth Data. Publication T1803.38. Washington State Transportation Commission and Transportation Northwest, March 2002.

9. Wang, Y., N. Nihan, R. Avery, and G. Zhang. Improving Truck and Speed Data Using Paired Video and Single-Loop Sensors. Publication T2695.61. Washington State Transportation Commission and Transportation Northwest, December 2006.

10. Monsere, C., M. Wolfe, H. Alawakiel, and M. Stephens. Developing Corridor Level Truck Travel Time Estimates and Other Freight Performance Measures from Archived ITS Data. Oregon Department of Transportation, Oregon Transportation Research and Education Consortium, August 2009.

11. Greaves, S. and M. Figliozzi. Vehicle Tour Data with Passive Global Positioning System Technology: Issues and Potential Applications. Transportation Research Record: Journal of the Transportation Research Board, No. 2049, Transportation Research Board of the National Academies, Washington, D.C., 2008, pp. 158-166.

12. Figliozzi. M, and Saberi, M. Travel Time Estimations on Congested Freeways with Stochastic Capacity, Working Paper, Portland State University.

13. Wheeler, N. and M. Figliozzi. Multi-Criteria Trucking Freeway Performance Measures in Congested Corridors, Forthcoming Transportation Research Record 2011.

14. Trego, T., and D. Murray. An Analysis of the Operational Costs of Trucking. In 89th 
Annual Meeting of Transportation Research Board. CD-ROM. Transportation Research Board of the National Academies, Washington, D.C., 2010.

15. ODOT. The Value of Travel Time: Estimates for the Hourly Value of Time for Vehicles in Oregon 2005. Oregon Department of Transportation Economics \& Policy Analysis Unit, 2006. 


\section{LIST OF TABLES}

TABLE 1 Segment Summary Information From Northbound Interstate 5 - July 2007 GPS Data

TABLE 2 Segment Travel Time Distributions For July 2007 - Interstate 5 NB Data And a 24Hour Time Period

TABLE 3 Segment Travel Time Distributions For July 2007 - Interstate 5 NB Data During Evening Hours (15:30:00 - 18:30:00) 


\section{LIST OF FIGURES}

FIGURE 1 Truck counts across segments for months April—spring, July—summer, Octoberfall and December-winter.

FIGURE 2 From left to right: A) Cumulative truck count plot, B) Cumulative truck count plot smoothed utilizing a 20 mile moving average.

FIGURE 3 Identified segments along Interstate 5 with Highway Performance Monitoring System (HPMS) volume data.

FIGURE 4 Segment 1 travel time distributions, 24 hour vs, 15:30 to 18:30 period (dashed lines show the corresponding $95^{\text {th }}$ percentile)

FIGURE 5 Segment 8 travel time distributions, 24 hour vs, 15:30 to 18:30 period (dashed lines show the corresponding $95^{\text {th }}$ percentile)

FIGURE 6 All segments travel time coefficients of variation of speed parameter $\mathbf{s}_{\min , i}$

FIGURE 7 From left to right, A) daily operating cost per mile per freight vehicle; B) additional daily travel time cost per mile per freight vehicle due to unreliable travel time only.

FIGURE 8 Percent increase in cost per mile per freight vehicle relative to free-flow costs for travel times at $50 \%, 80 \%$, and $95 \%$ percentiles. 


\section{Truck counts per segment per month}

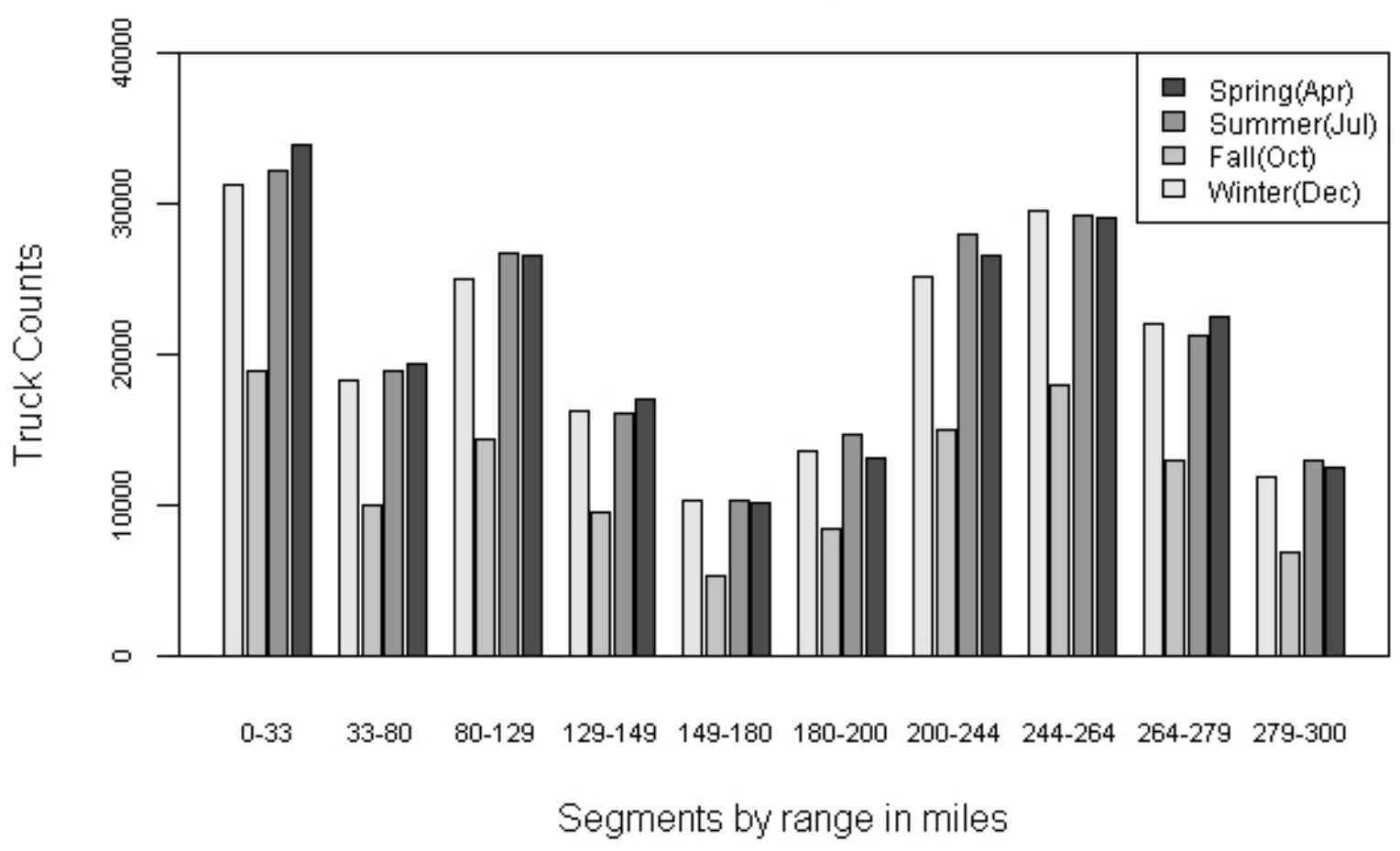

FIGURE 1 Truck counts across segments for the following months: April(spring), July (summer), October (fall) and December (winter). 

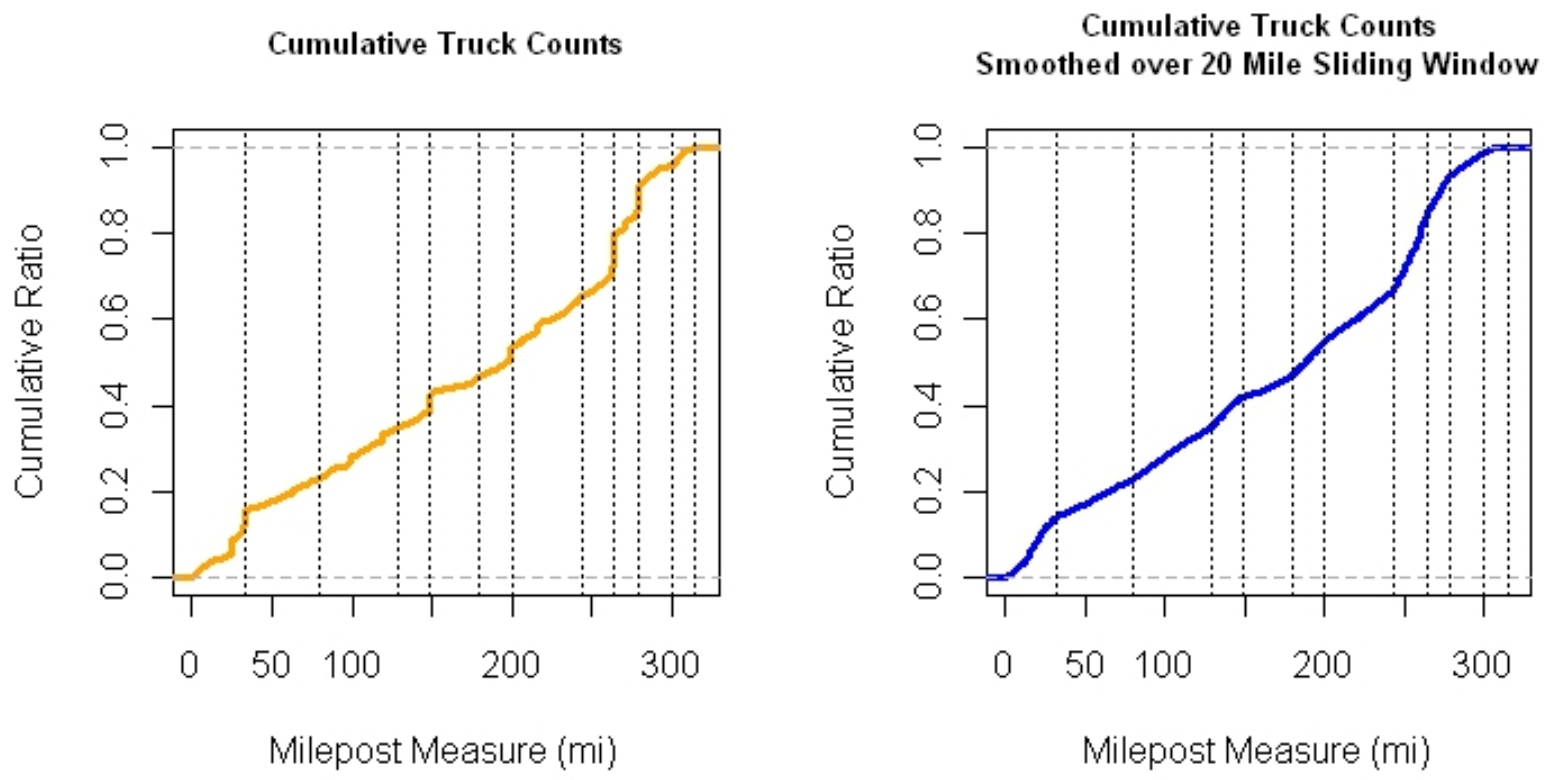

FIGURE 2 From left to right: A) Cumulative truck count ratio, B) Cumulative truck count ratio smoothed utilizing a 20 mile moving average. 
TABLE 1 Segment Summary Information Northbound Interstate 5 - July 2007 GPS Data

\begin{tabular}{|c|c|c|l|}
\hline $\begin{array}{c}\text { Segment } \\
\text { ID }\end{array}$ & $\begin{array}{c}\text { Segment } \\
\text { mileposts }\end{array}$ & $\begin{array}{c}\text { Truck } \\
\text { counts }\end{array}$ & \multicolumn{1}{|c|}{ Nearby locations on I-5 NB } \\
\hline 1 & $0-33$ & 18,861 & $\begin{array}{l}\text { Pacific Hwy 99, Crater Lake Hwy, and International Medford- } \\
\text { Airport }\end{array}$ \\
\hline 2 & $33-80$ & 9,998 & Pacific Hwy 99 \\
\hline 3 & $80-129$ & 14,392 & Pacific Hwy, NE Stephens St, Roseburg Airport \\
\hline 4 & $129-149$ & 9,454 & Pacific Hwy, Eagle Valley Rd, Umpqua Hwy 99 \\
\hline 5 & $149-180$ & 5,284 & Near Eugene \\
\hline 6 & $180-200$ & 8,427 & Near Eugene \\
\hline 7 & $200-244$ & 14,929 & Eugene-Corvallis \\
\hline 8 & $244-264$ & 18,002 & Salem, Woodburn \\
\hline 9 & $264-288$ & 12,898 & Wilsonville, Tualatin, Junction I-205 \\
\hline 10 & $288-300$ & 6,892 & Portland Junction I-84 (Figure 3A) \\
\hline
\end{tabular}




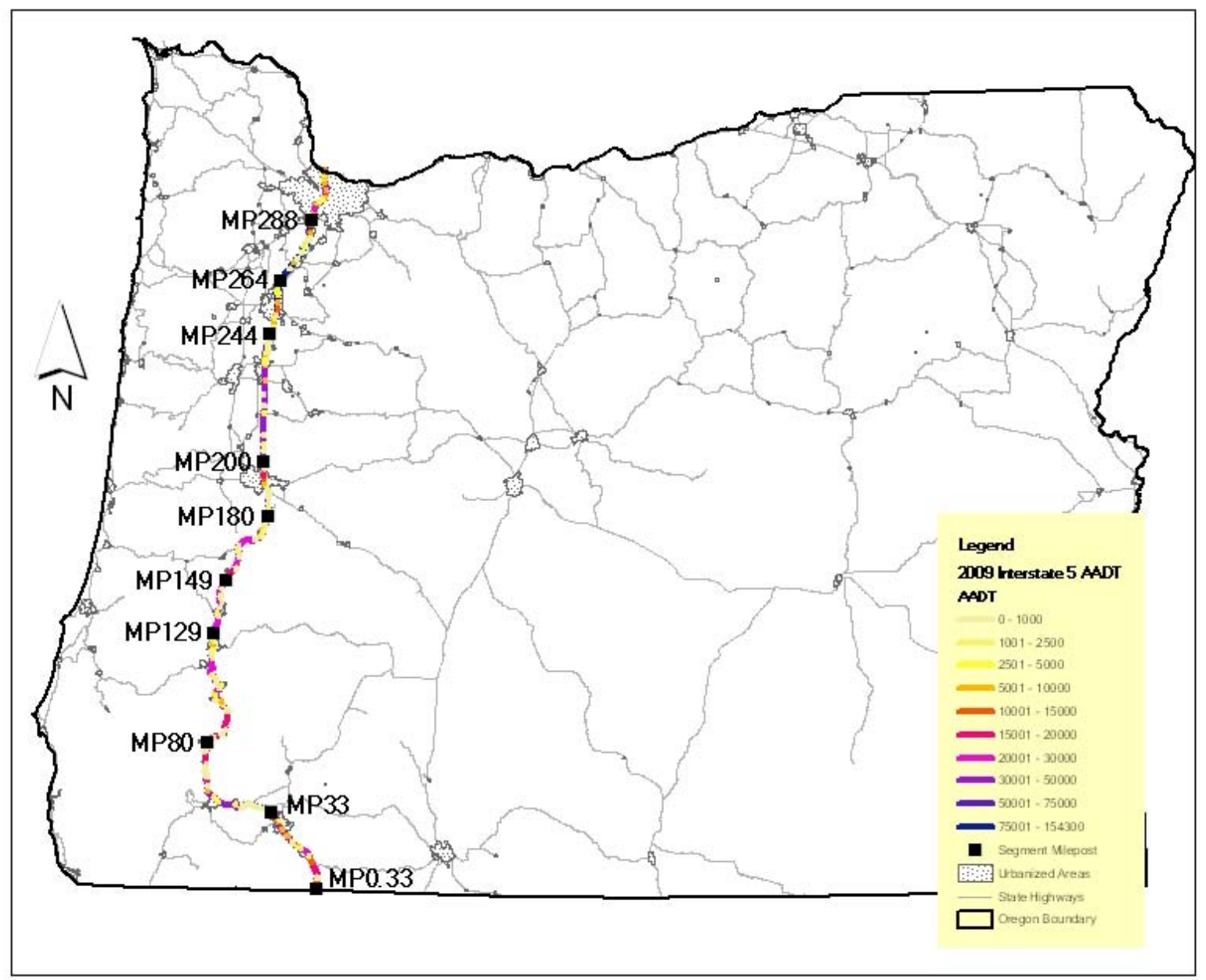

FIGURE 3 Identified segments along Interstate 5 utilizing Highway Performance Monitoring System (HPMS) volume data. 
TABLE 2 Segment Travel Time Distributions for July 2007 - Interstate 5 NB Data During 0:00-24:00 Hour Time Period

\begin{tabular}{|c|c|c|c|c|c|c|c|c|}
\hline $\begin{array}{c}\text { Segment } \\
\text { ID }\end{array}$ & $\begin{array}{c}\mathbf{m}_{\mathbf{0}} \\
\text { (miles) }\end{array}$ & $\begin{array}{c}\mathbf{m}_{\mathbf{1}} \\
\text { (miles) }\end{array}$ & $\begin{array}{c}\mathbf{b}_{\mathbf{r}} \\
\text { (miles) }\end{array}$ & $\begin{array}{c}\mathbf{n}_{\text {actual }} \\
\text { (count) }\end{array}$ & $\begin{array}{c}\text { Free-flow } \\
\text { (hrs) }\end{array}$ & $\begin{array}{c}\text { Median,t } \\
\text { (hrs) }\end{array}$ & $\begin{array}{c}\mathbf{t}_{\mathbf{8 0}} \\
\text { (hrs) }\end{array}$ & $\begin{array}{c}\mathbf{t}_{\mathbf{9 5}} \\
\text { (hrs) }\end{array}$ \\
\hline 1 & 3 & 33 & 3 & 371 & 0.5 & 1.23 & 1.48 & 1.77 \\
\hline 2 & 33 & 80 & 4.7 & 591 & 0.78 & 1.48 & 1.77 & 2.09 \\
\hline 3 & 80 & 129 & 4.9 & 331 & 0.82 & 1.48 & 1.82 & 2.19 \\
\hline 4 & 129 & 149 & 2 & 155 & 0.33 & 0.74 & 0.918 & 1.11 \\
\hline 5 & 149 & 180 & 3.1 & 216 & 0.52 & 1.22 & 1.49 & 1.8 \\
\hline 6 & 180 & 200 & 2 & 54 & 0.33 & 0.686 & 0.831 & 0.991 \\
\hline 7 & 200 & 244 & 4.4 & 309 & 0.73 & 1.86 & 2.39 & 2.98 \\
\hline 8 & 244 & 264 & 2 & 151 & 0.33 & 0.799 & 0.988 & 1.2 \\
\hline 9 & 264 & 279 & 1.5 & 268 & 0.25 & 0.828 & 1.01 & 1.22 \\
\hline 10 & 279 & 300 & 2.1 & 99 & 0.35 & 1.11 & 1.36 & 1.64 \\
\hline
\end{tabular}

TABLE 3 Segment Travel Time Distributions for July 2007 - Interstate 5 NB Data During 15:30- 18:30 Time Period

\begin{tabular}{|c|c|c|c|c|c|c|c|c|}
\hline $\begin{array}{c}\text { Segment } \\
\text { ID }\end{array}$ & $\begin{array}{c}\mathbf{m}_{\mathbf{0}} \\
\text { (miles) }\end{array}$ & $\begin{array}{c}\mathbf{m}_{\mathbf{1}} \\
\text { (miles) }\end{array}$ & $\begin{array}{c}\mathbf{b}_{\mathbf{r}} \\
\text { (miles) }\end{array}$ & $\begin{array}{c}\mathbf{n}_{\text {actual }} \\
\text { (count) }\end{array}$ & $\begin{array}{c}\text { Free-flow } \\
\text { (hrs) }\end{array}$ & $\begin{array}{c}\text { Median,t } \\
\text { (hrs) }\end{array}$ & $\begin{array}{c}\mathbf{t}_{\mathbf{8 0}} \\
\text { (hrs) }\end{array}$ & $\begin{array}{c}\mathbf{t}_{\mathbf{9 5}} \\
\text { (hrs) }\end{array}$ \\
\hline 1 & 3 & 33 & 3 & 40 & 0.5 & 1.07 & 1.24 & 1.43 \\
\hline 2 & 33 & 80 & 4.7 & 55 & 0.78 & 1.4 & 1.63 & 1.88 \\
\hline 3 & 80 & 129 & 4.9 & 26 & 0.82 & 1.09 & 1.2 & 1.32 \\
\hline 4 & 129 & 149 & 2 & 21 & 0.33 & 0.707 & 0.853 & 1.02 \\
\hline 5 & 149 & 180 & 3.1 & 13 & 0.52 & 0.775 & 0.912 & 1.06 \\
\hline 6 & 180 & 200 & 2 & 11 & 0.33 & 0.765 & 0.911 & 1.07 \\
\hline 7 & 200 & 244 & 4.4 & 21 & 0.73 & 1.13 & 1.34 & 1.57 \\
\hline 8 & 244 & 264 & 2 & 14 & 0.33 & 0.773 & 0.955 & 1.16 \\
\hline 9 & 264 & 279 & 1.5 & 32 & 0.25 & 0.781 & 0.952 & 1.14 \\
\hline 10 & 279 & 300 & 2.1 & 6 & 0.35 & 0.944 & 1.12 & 1.33 \\
\hline
\end{tabular}


Probability Distribution Segment 1(0-33 Miles)

0:00-24:00 and 15:30-18:30 Hour Trips

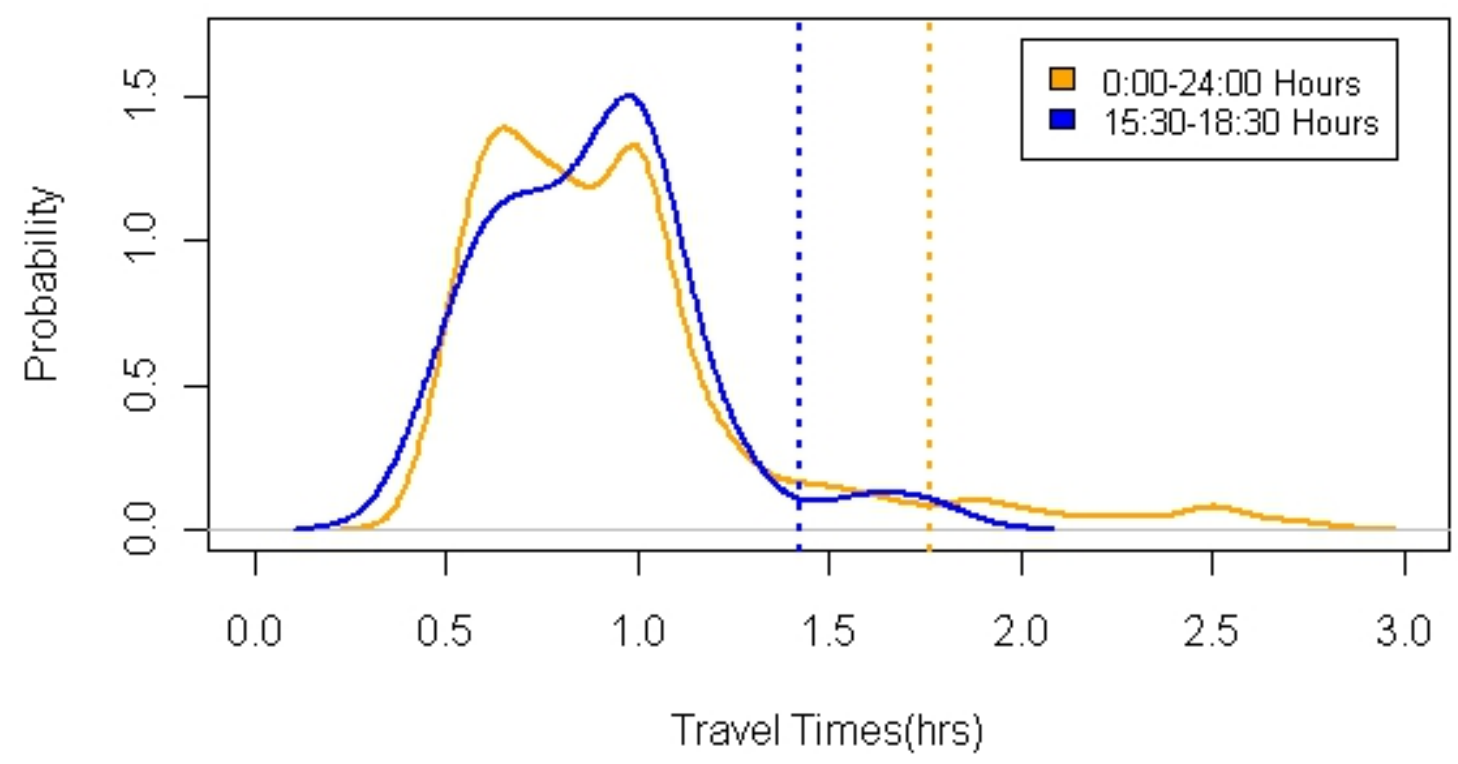

FIGURE 4 Segment 1 travel time distributions, 24 hour vs, 15:30 to 18:30 period (dashed lines show the corresponding $95^{\text {th }}$ percentile) 


\section{Probability Distribution Segments 8(244-264 Miles) \\ 0:00-24:00 and 15:30-18:30 Hour Trips}

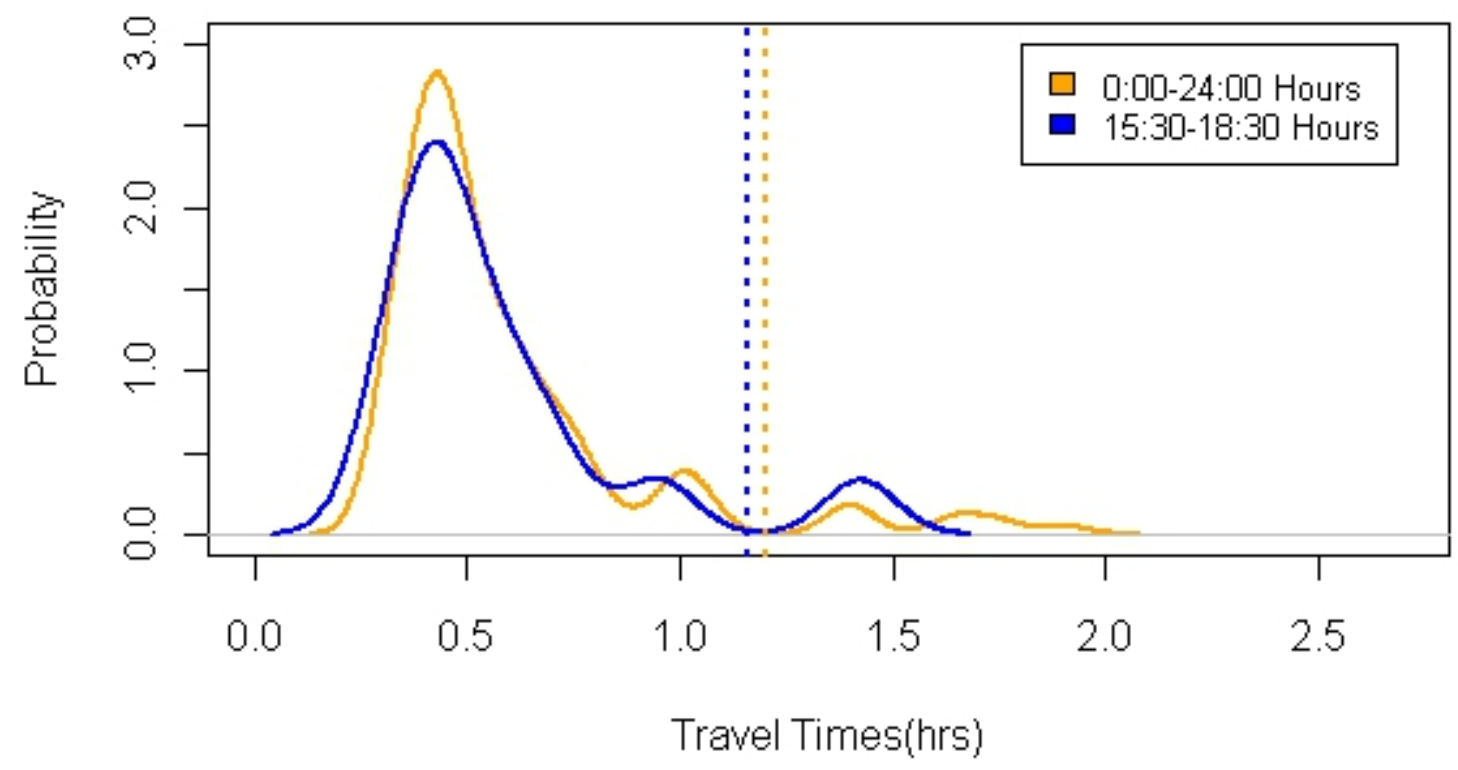

FIGURE 5 Segment 8 travel time distributions, 24 hour vs, 15:30 to 18:30 period (dashed lines show the corresponding $95^{\text {th }}$ percentile) 


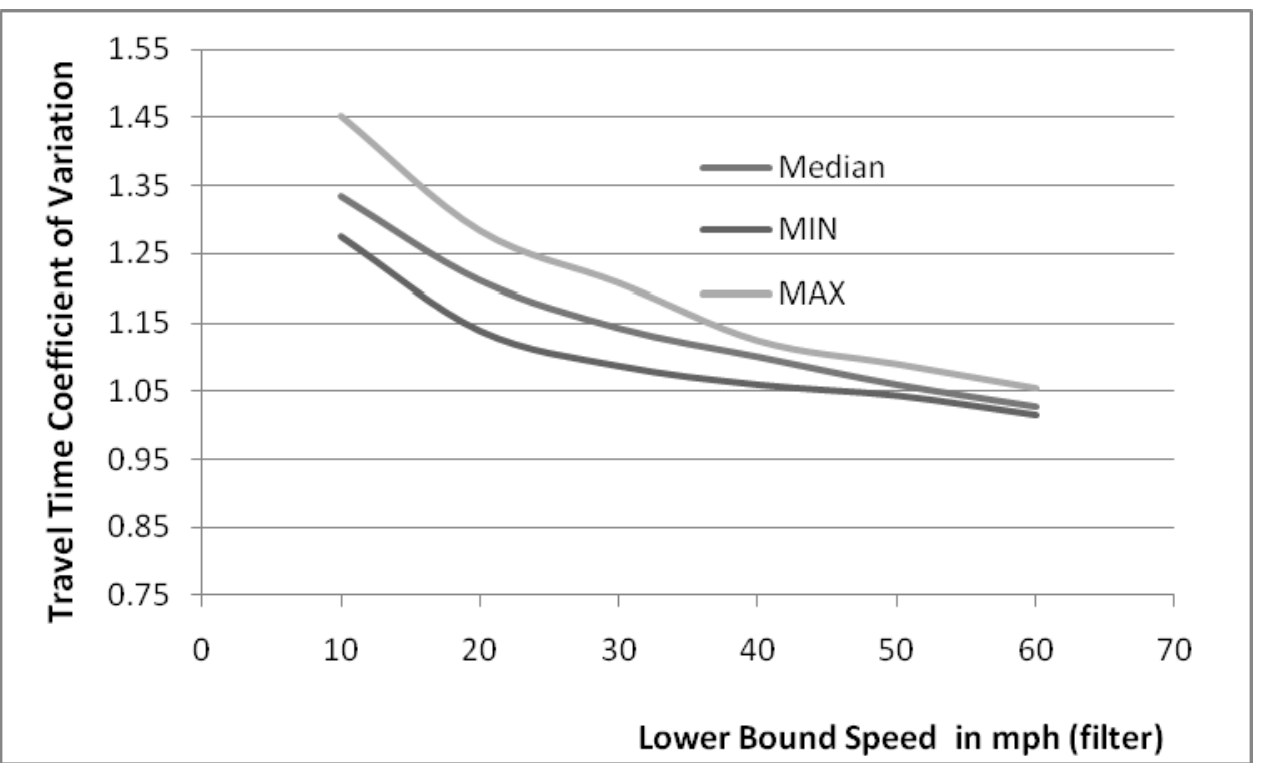

FIGURE 6 All segments travel time coefficients of variation of speed parameter $s_{\text {min,i }}$ 

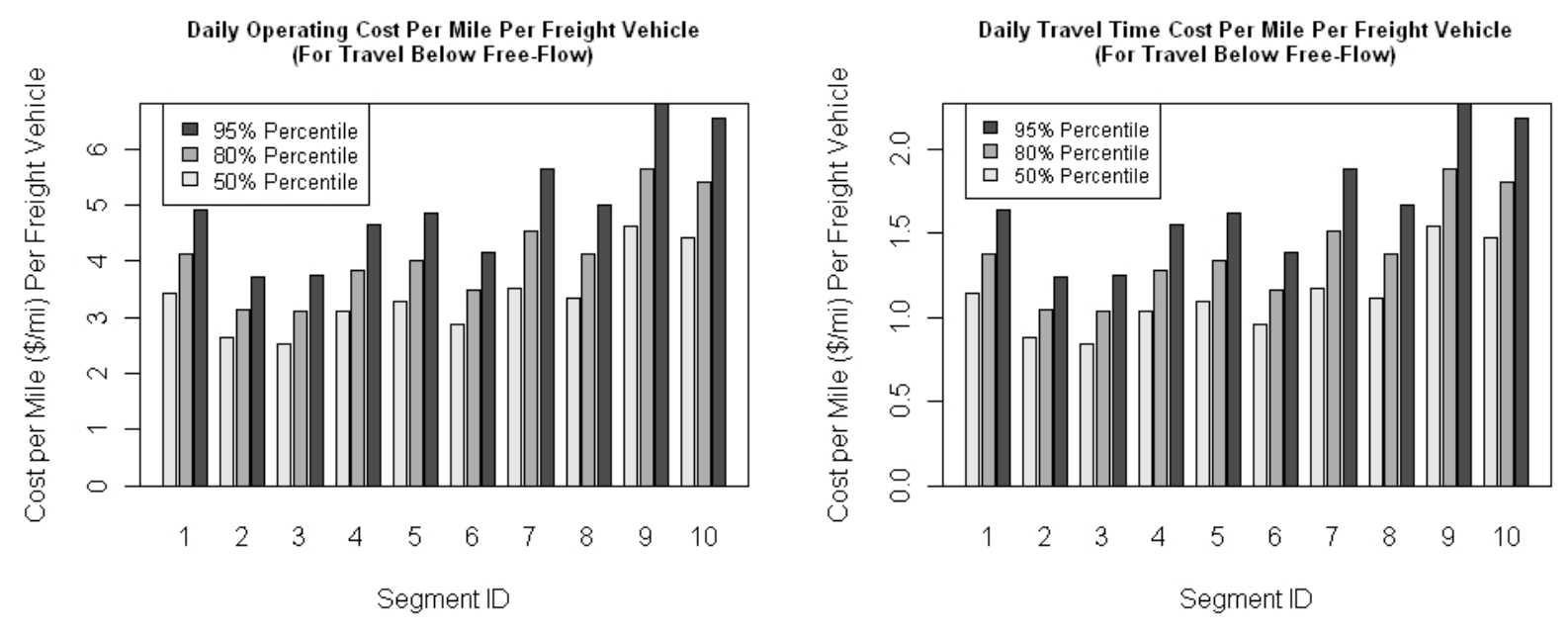

FIGURE 7 From left to right, A) daily operating cost per mile per freight vehicle; B) additional daily travel time cost per mile per freight vehicle due to unreliable travel time only. 


\section{Percent Increase in Cost per Mile Per Freight Vehicle}

Relative to Free-Flow conditions

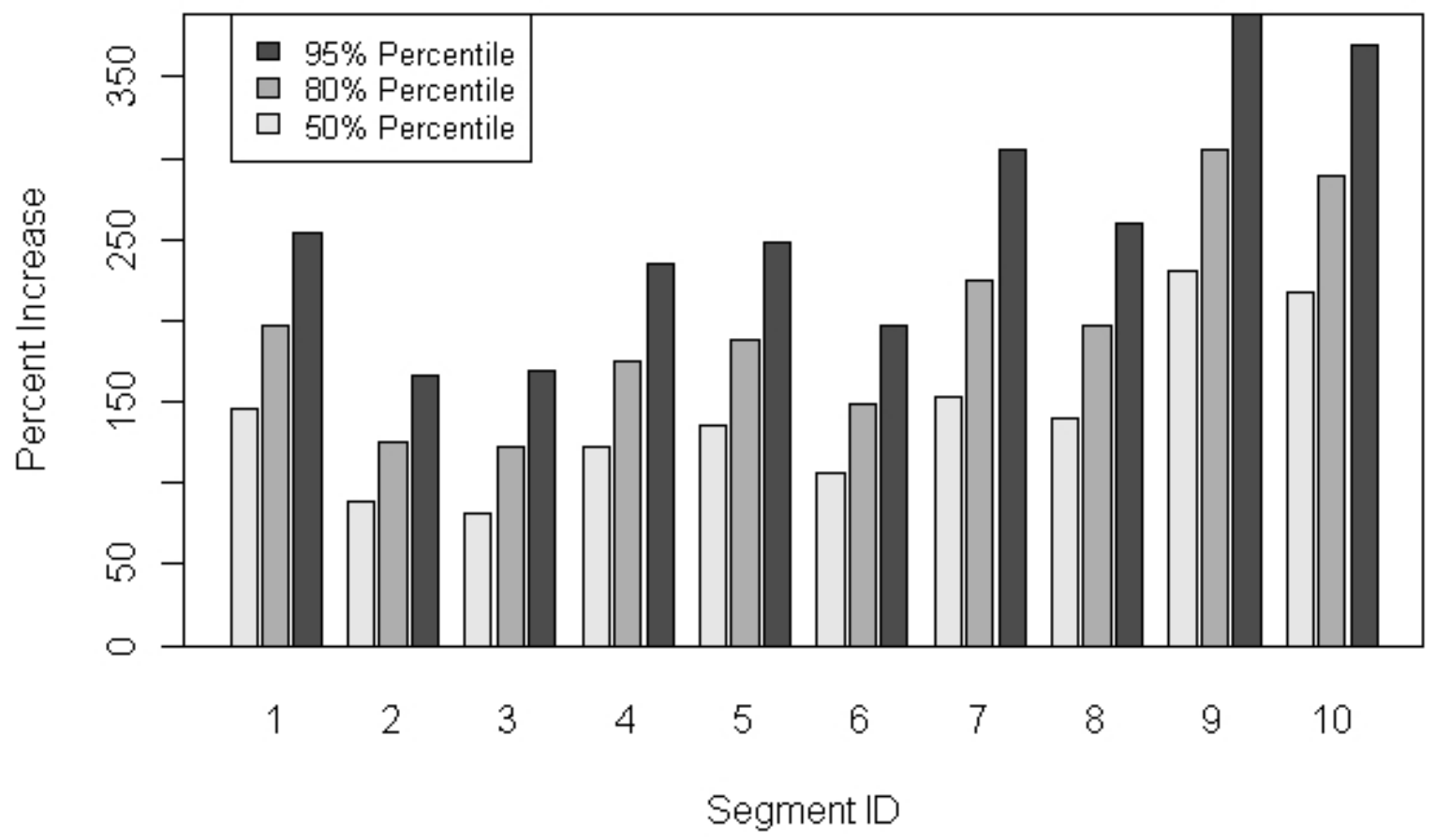

FIGURE 8 Percent increase in cost per mile per freight vehicle relative to free-flow costs for travel times at $50 \%, 80 \%$, and $95 \%$ percentiles. 